\title{
Fonologia: ferramenta de ensino para professores de inglês como língua estrangeira
}

\author{
Valdirécia de Rezende Taveira \\ Universidade Federal de Minas Gerais/CAPES \\ Clarice Lage Gualberto \\ Universidade Federal de Minas Gerais
}

\begin{abstract}
Resumo
Neste ensaio, pretendemos propor uma reflexão sobre o uso dos conhecimentos de fonologia como ferramenta para professores de inglês como língua estrangeira. Uma das dificuldades de quem estuda uma língua estrangeira (LE) está relacionada à produção e compreensão oral nessa LE, já que cada língua apresenta características particulares, seja na organização sintática, seja na organização fonética, seja na prosódia. Além disso, não raro, a língua estrangeira apresenta fonologia (sons) e prosódia que não coincidem com as da língua materna. Desta forma, considerando-se este processo, o estudo/aprendizagem da fonologia pode ser um importante aspecto na busca de tornar esta tarefa menos difícil e mais efetiva.
\end{abstract}

Palavras-chave: língua inglesa; fonologia; ensino

\begin{abstract}
In this essay, we reflect on the use of the knowledge of phonology as a tool for teachers of English as a Foreign Language. One of the difficulties of those who study a foreign language (FL) is related to oral production and listening skills, as each language has unique characteristics, in the syntactic organization, in the phonetic organization, and in prosody. Moreover, not infrequently, the foreign language has phonology (sounds) and prosody that do not match those of the mother language. Thus, considering this process, the study of phonology can be an important way to make the task of teaching English easier and more effective.
\end{abstract}

Keywords: English language; phonology; learning

\section{INTRODUÇÃO}

A fonologia é a parte da linguística que estuda os sistemas sonoros das línguas, ou seja, a categorização de sons e os aspectos relacionados com a percepção. A fonologia 
inclui o estudo de como os sons são usados sistematicamente em uma determinada língua, incluindo padrões de entonação e prosódia, assim como a fonética.

A fonologia dedica-se a diferentes aspectos relacionados à sonoridade da língua. Há autores que se dedicam a estudar fatores como entonação e acento considerando-os como autônomos em relação à estrutura segmental da frase. Outros trabalham com a fonologia aplicada ao léxico. Há ainda estudiosos que se dedicam à organização de segmentos em palavras e há autores que trabalham com o estudo da fala caracterizada em fonemas. Como podemos perceber, o campo da fonologia é um campo amplo que trabalha com diferentes aspectos da língua.

Neste sentido, como cada língua apresenta características específicas de sonoridade, seja considerando-se a articulação dos sons, seja a prosódia ou a entonação, acreditamos haver muitas vantagens em trabalhar com fonologia em aulas/cursos de Inglês como língua estrangeira (LE).

\section{A FONOLOGIA COMO FERRAMENTA DE ENSINO DE LE.}

O estudo da fonologia pode ser uma poderosa ferramenta de aprendizagem para o desenvolvimento das competências linguísticas, tais como ouvir e falar. Mesmo que se possa dizer que compreensão e produção oral podem ser desenvolvidas apenas pela prática, os alunos e professores podem utilizar fonologia como uma ferramenta para ajudar no desenvolvimento dessas habilidades.

Primeiramente, vamos considerar características fonológicas em geral e padrões subjacentes à segunda língua. Apesar de que se possa argumentar que saber características fonológicas não é suficiente para melhorar a sua pronúncia, pesquisas mostram que conhecer as características fonológicas quando se estuda uma língua estrangeira pode ser eficaz no processo de aprendizagem. Embora não seja a solução para todos os problemas de aprendizagem de pronúncia, a fonologia pode ser usada como uma importante ferramenta neste processo. Miller (2002) mostra que os aprendizes costumam ter falta de informação acerca da pronúncia na língua estrangeira. Não raro, em aulas de inglês para estrangeiros, a parte dedicada à pronúncia em geral se resume a praticar pronúncia pela repetição de 
palavras ou pequenas sentenças. Raramente os alunos recebem informação sobre a qualidade de sons, padrão de entonação e similares. Com isso, muitos aprendizes falam Inglês usando padrões de entonação errados e, normalmente, pronunciam palavras simples de forma errada. Como resultado, muitos alunos ficam frustrados com o seu processo de aprendizagem. Diante disso, entendemos que conhecer os fundamentos do sistema fonológico do Inglês enquanto língua estrangeira pode ser efetivo na busca de levar os alunos a tornar-se conscientes da pronúncia correta e capazes de monitorar a própria fala. Se os alunos não tiverem a consciência fonológica da LE, eles não saberão como monitorar seu discurso, sempre irão precisar de alguém para corrigir a sua pronúncia.

Para o ensino de fonologia como ferramenta de ensino/aprendizagem de LE, devemos considerar as características fonéticas de uma língua. A fonética é a parte da fonologia que se dedica ao estudo articulatório e acústico da fala. Na fonética, o principal aspecto que nos interessa é o inventário fonético internacional - ou IPA (International Phonetics Alphabet) - que é o inventário de símbolos convencionais para representar os sons da fala.

Nem todos os sons do IPA estão presentes em todas as línguas. Segundo Silva (2012, p.117), "línguas variam quanto aos seus inventários fonéticos", ou seja, o inventário fonético de uma língua não corresponde ao de outra, o que implica que há sons existentes em uma língua que não existem necessariamente em outra. Assim, estudando fonologia da LE, os alunos podem tornar-se conscientes das características fonéticas. A fala apresenta alguns princípios em sua organização sonora. Ainda segundo Silva (ibid), "[T]ais princípios agrupam segmentos consonantais e vocálicos em cadeia e de terminam a organização das sequências sonoras possíveis de uma determinada língua”. Assim, cada língua apresenta uma organização sonora específica. Ainda segundo a autora, todo falante possui uma intuição acerca do sistema sonoro de sua língua - poderíamos acrescentar, obviamente, que, então, não o possuem em relação a línguas estrangeiras.

Diante disso, acreditamos ser necessário e produtivo que alunos de inglês como LE conheçam o IPA. Apesar do trabalho em sala de aula para ensinar o IPA exigir mais tempo que o habitual, estudando a fonética da LE, os alunos podem ter autonomia para procurar não só o significado, mas também a pronúncia de palavras em dicionários, uma vez que 
estes geralmente trazem a transcrição fonética das palavras. Por outro lado, pode-se argumentar que é um pouco difícil porque há muitas convenções sobre a representação de sons e os alunos não podem aprender todas as convenções. No entanto, quando o aluno estuda o alfabeto fonético e sabe que há símbolos que representam sons da fala, é mais fácil entender a transcrição nos dicionários. Além disso, dicionários e livros didáticos de LE geralmente trazem na capa uma lista de palavras e o som correspondente para ilustrar para o usuário dessas matérias, qual sistema convencional foi seguido. Assim, o aluno não precisa aprender todas as convenções, mas deve saber que existem símbolos para representar sons e como verificar esses símbolos no material que irá usar.

Não estamos argumentando aqui que se deve ensinar o IPA e cobrar do aluno que conheça a diferença das consoantes em termos de classificação (fricativas, lábio-dental, palatal). O que queremos dizer é que o IPA pode e deve ser usado como ferramenta de aprendizagem para um aluno de inglês como LE, não somente para ajudar no aperfeiçoamento da pronúncia, mas também para desenvolver uma autonomia no aluno em relação a essa habilidade.

Outro item importante em que a fonologia poderia ser usada é no conhecimento de sons que são distintivos em uma língua e não em outra. Por exemplo, em português o fonema /t/ realiza-se foneticamente como [t] ou [t $\left.\int\right]$, dependendo da posição em que ocorre na palavra: se diante da vogal [i], teremos o [t]], como na palavra tia; se diante das demais vogais, o fonema /t/ realiza-se [t] como na palavra teto. Entretanto, voltemos à palavra tia. Dependendo da região do Brasil o /t/ nessa palavra poderá ser realizado como [t] ou [t $\left.\int\right]$ não causando nenhuma estranheza ou incompreensão a nenhum falante do português. Por outro lado, na língua inglesa esses sons não podem ser usados como equivalentes. Erro comum acontece na palavra teacher em que falantes brasileiros costumam pronunciar o fonema /t/ que aparece $\left[\mathrm{t} \int\right]$ ao invés de $[\mathrm{t}]$, que seria o correto na primeira ocorrência na palavra em questão. Essa pronúncia, com [t $\left.\int\right]$ é inaceitável no inglês e dificilmente seria reconhecida por um falante nativo da língua. 
O DETYA (Department of education training and youth affairs) desenvolveu um curso para o ensino de pronúncia e detectou que o ensino de fonemas e prosódia, ambos parte da fonologia, são de fundamental importância para o ensino/ prática de inglês como língua estrangeira. Segundo Frase (2001, p.5), é necessário focar tanto características como entonação e ritmo quanto focar características fonéticas, inclusive porque muitas vezes as características fonéticas irão interferir no ritmo e entonação. Além disso, a autora ainda enfatiza que a fonologia pode ser ensinada a aprendida de forma eficiente. Segundo a autora,

Na prosódia, assim como ocorre com os fonemas, a influência inconsciente de nossa primeira língua é imensa na formação da nossa percepção e concepção, de forma que as pessoas de diferentes origens linguísticas compreendem aspectos prosódicos de forma bastante diferente. ${ }^{1}$ FRASER $(2001, \mathrm{p} 30)$

Com isso, delineia-se importante o ensino de aspectos da prosódia na LE de forma a tornar o aluno consciente das características da língua que estuda. Ainda segundo a autora, o ponto chave para a dificuldade de falar uma língua estrangeira (aqui nos referimos à produção oral), está no fato de que os alunos não aprendem a falar apenas ao serem apresentados a fatos a respeito da língua. Ao contrário, eles aprendem ao serem guiados por experiências que os levem a construir conceitos a respeito da língua em seu subconsciente, de forma a minimizar a influência da primeira língua quando se aprende uma língua estrangeira. Gilbert (2008) pontua que o conhecimento da prosódia da LE por parte de professores e alunos é fundamental para o desenvolvimento das habilidades de produção oral. Assim, afirma o autor,

Em Inglês, sinais rítmicos e melódicos servem como "sinais de trânsito" para ajudar o ouvinte a entender as intenções do falante. Estes sinais comunicam a ênfase e tornam clara a relação entre as ideias para que os ouvintes possam identificar facilmente essas relações e entender o que o falante quer dizer. Infelizmente, quando os alunos de língua inglesa falam em sala de aula, eles geralmente não pensam em como ajudar os seus

\footnotetext{
${ }^{1}$ Tradução nossa para "In prosody, as with phonemes, the subconscious influence of our first language is immense in shaping our perception and conception, so people from different language backgrounds hear prosody quite differently."
} 
ouvintes a entender o querem dizer. Em vez disso, eles muitas vezes pensam sobre como evitar erros de gramática, vocabulário, e assim por diante ${ }^{2}$ (GILBERT, 2008, p.2).

Isso nos mostra a importância do trabalho em sala de aula de aspectos prosódicos da língua como forma de mostrar ao aluno como "falar corretamente", não para parecer um nativo, mas para ser compreendido por qualquer falante da língua inglesa.

De acordo com Pennington (1996), a fonética é muito útil para a prática de listening. O aluno, conhecedor da fonética de uma língua, pode prestar atenção a sons específicos e reconhecer as palavras mais facilmente, assim como reconhecer as palavras importantes em vez de tentar entender todas as palavras e toda a frase. Trata-se de aspecto importante e que ajuda muito, não só nas atividades de listening, mas também em atividades de prática oral, como por exemplo, saber as diferenças básicas entre os sons como consoantes surdas e sonoras; vogais longas e curtas, porque estas distinções raramente são ensinadas e estudantes de inglês como LE costumam ter dificuldades para fazer essas distinções. Como exemplo, podemos citar as palavras it e eat, em que a primeira apresenta o som da vogal /i/ curto e a segunda um som longo da mesma vogal. É uma diferença talvez muito sutil para um estrangeiro, mas para um nativo é bastante diferente e significativo. O não conhecimento dessas características pode causar estranhamento em interações nativo/estrangeiro. Nesse sentido, se os alunos não conhecem essas pequenas diferenças entre sons consonantais e sons vocálicos, é difícil entender algumas palavras e pronunciá-las.

Além disso, Pennington (1996, p.222) argumenta que sobre a pronúncia de sons individuais podem aumentar a inteligibilidade das palavras individuais. Como exemplo, para um falante do Português, é às vezes difícil de pronunciar o th em palavras como think, that e with. Isso porque o [ $\theta]$ e o [ð] são sons que não existem em português, por isso, eles costumam pronunciar [s] [d] e [f], respectivamente. Para um brasileiro falante do português conversando com outro brasileiro, talvez não haja problemas, mas para um falante nativo

\footnotetext{
${ }^{2}$ Tradução nossa para: "In English, rhythmic and melodic signals serve as "road signs" to help the listener follow the intentions of the speaker. These signals communicate emphasis and make clear the relationship between ideas so that listeners can readily identify these relationships and understand the speaker's meaning. Unfortunately, when English learners speak in class, they are typically not thinking about how to help their listeners follow their meaning. Instead, they are often thinking about avoiding mistakes in grammar, vocabulary, and so on"
} 
da língua inglesa, esta troca de sons é considerável na compreensão da fala. Dessa forma, conhecer o inventário de sons da fala inglês pode ajudar os alunos a entender as diferenças entre sons e se auto-monitorar quando estiver falando a LE.

Além disso, os padrões de entonação do inglês ajudam o falante a demonstrar interesse ou desinteresse na conversa. Trata-se, assim, de um aspecto importante na construção do significado, quando tratamos da linguagem oral. Se os alunos não têm essa consciência pode parecer chato e desinteressado. Como exemplo, podemos citar os casos de entonação ascendente e descendente, que na língua inglesa expressam significados. Assim, uma entonação ascendente em Really! mostra que o ouvinte está interessado na conversa e uma entonação descendente mostra o contrário, ou seja, desinteres se na conversação. Se um aluno de inglês como LE não conhece essa diferença, quando usar a língua estrangeira utilizando os padrões de entonação da própria língua, este pode causar estranheza em seus interlocutores mostrando-se interessado o tempo todo ou parecer dar muita atenção, sem necessidade, ou, ainda, parecer desinteress ado na comunicação.

Vale ainda ressaltar a importância do uso da fonologia como ferramenta de ensinoaprendizagem considerando-se as palavras tônicas nas sentenças. Às vezes, podem-se causar incompreensões na fala uma vez que na língua inglesa as palavras tônicas na sentença apresentam informações sobre o tema da conversa. Por exemplo, em uma conversa em que alguém pronuncia a frase We went to the cinema yesterday night e a palavra acentuada seja cinema, indica que o tema da conversa é a atividade de ontem à noite. Por outro lado, seria diferente se a ênfase fosse em night, pois significaria que o tema de conversa seria quando ir ao cinema: à tarde ou à noite, por exemplo. Assim, o aluno que não tiver essa informação pode ter dificuldades em compreender outros falantes de língua inglesa e ter um lugar em uma conversa.

Dessa forma, a fonologia pode ajudar os alunos a adquirir fluência. Embora algumas pessoas acreditem que a fluência pode ser adquirida apenas quando exposto à linguagem oral em situação real, quer dizer, conversando com nativos, em um país que tenha o inglês como língua oficial, isso não é verdade. Através de aspectos fonológicos mencionados anteriormente, associados à prática, os alunos podem adquirir fluência em sala de aula. Ufomata, (1996) mostra, em seu artigo "Setting priorities in teaching English 
pronunciation in ESL context", que os alunos que estudam a fonologia e a usam para praticar o Inglês fora da sala de aula, adquiriram fluência com menos dificuldade que aqueles que apenas praticaram em sala de aula e, também, aqueles que não estudaram fonologia. Além disso, ele associa a aquisição de fluência à sua prática. Então, o que é necessário para atingir essa meta? Basta praticar? A resposta é não. Isso porque praticando

a pronúncia errada não irá desenvolver fluência. É necessário que o aluno sa iba/aprenda a qualidade de sons em inglês, regras de padrões de entonação, sílabas tônicas e palavras tônicas em sentenças. E esse conhecimento pode ser adquirido através do estudo de fonologia.

Em conclusão, ensinando fonologia, professores de inglês como LE têm muitas vantagens, como ajudar os aprendizes não só na sua pronúncia, mas também em suas habilidades de escuta e fala, permitindo aos alunos que verifiquem em dicionários a pronúncia de palavras e estejam cientes das características fonológicas e padrões de entonação da língua estrangeira que estão aprendendo. Argumentamos que, estudando fonologia, os alunos podem desenvolver consciência das características que envolvem os sons na língua estrangeira, das diferenças de entonação, ou seja, algumas das ferramentas que irão auxiliá- los no desenvolvimento de habilidades como a fala e a compreensão oral.

\section{REFERÊNCIAS}

Fraser, H. (2001). Teaching Pronunciation: A handbook for teachers and trainers Three Frameworks for an Integrated Approach. Australia: DETYA

Gilbert. J.B. (2008). Teaching pronunciation. Using the prosody pyramid. New York: Cambridge University Press.

Miller, G. V. (2002). Reflective Practice in Pronunciation Learning. The Internet TESL Journal, Vol. VIII, No. 1. Disponível em: <http://www. usingenglish.com/> Acessado em: $10 / 06 / 2012$

Penington, M. (1996). Phonology in English Language Teaching. London and New York: Longman.

Silva.T.C. (2012). Fonética e fonologia do português. Roteiro de estudos e guia de exercícios. São Paulo: Editora Contexto. 
Ufomata, T. (1996). Setting Priorities in Teaching English Pronunciation in ESL Contexts. Disponível em: http://www.phon.ucl.ac.uk/home/sh19/ufomata/titi.htm Acessado em $\underline{08 / 09 / 2012}$

\section{AS AUTORAS}

Valdirécia de Rezende Taveira é graduada em Letras (Inglês/Português) pela Universidade Federal de Minas Gerais. É mestranda em linguística pela mesma universidade e atua no ensino de língua inglesa.

E-mail: valdirecia@ hotmail.com

Clarice Lage Gualberto é graduada em Letras (Português) pela Universidade Federal de Minas Gerais. É mestre e doutoranda em linguística pela mesma universidade e atua no ensino de língua portuguesa.

E-mail: clagegual@ hotmail.com 